Philosophy and Progress: Vols. LIX-LX, January-June, July-December, 2016 ISSN 1607-2278 (Print), DOI : http://dx.doi.org/10.3329/pp.v59i1-2.36683

\section{AN OVERVIEW OF GAME THEORY AND SOME APPLICATIONS}

\section{Bellal Ahmed Bhuiyan*}

\section{Introduction}

Game theory is an autonomous discipline that is used in applied mathematics, social sciences, most considerably in economics, as well as in biology, engineering, political science, international relations, computer science and philosophy. Game theory is the mathematical study of strategy and conflict, in which an agent's success in making choices depends on the choice of others. It was initially developed in economics to understand a large collection of economic behaviors, including behaviors of firms, markets and consumers. Game theory has been used to attempt to develop theories of ethical or normative behavior as well. In economics and philosophy, scholars have applied game theory to help in the understanding of rational

\footnotetext{
* Lecturer, Department of Philosophy, University of Dhaka Email: anikbellal@du.ac.bd
}

behavior. The purpose of this paper is to clarify the following issues: firstly, to provide very brief overview of game and game theory; secondly, to discuss background and impact of game theory; thirdly, to analyze the prisoner's dilemma game and finally, to present applications of game theory with special attention to philosophy.

Key Words: game, game theory, strategy, prisoner's dilemma, philosophy.

\section{i. Game}

The 'game' is the object of studying in game theory. The complete set of rules describes a game. A play is an instance of the game. Most games played for fun, entertainment and leisure. When someone over reacts, we sometimes say 'it's just a game'. Checkers, chess, football, judo, and squash and thousands of other formalized contests are examples of games in which there are two players or teams. Most of these games have only one winner after played (Geckil, 2010). But there are many other situations that can be formulated as games. A game follows as:

A game is an abstract, which is defined as a formal description of a strategic situation. Any strategic interaction involves two or more decision- makers (players), each with two or more ways of acting (strategies), such that the outcome depends on the strategy choices of all the players. Each player has welldefined preferences among all the possible outcomes, enabling corresponding utilities (payoffs) to be assigned. A game makes explicit the rules governing players' interactions, the players feasible strategies, and their preferences over outcomes (Bicchieri and Sillari, 2005, P. 296). 
All games have three essential elements- players, strategies, payoffs. So, a game in normal form consists of:

a) $\mathrm{A}$ (finite) number of players. $\mathrm{P}=\{1,2,3 \ldots, \mathrm{n}\}$, $\{\mathrm{P} 1, \ldots \ldots, \mathrm{Pn}\}$

b) A Strategy set Si assigned to each player: $\{\mathrm{S} 1, \ldots, \mathrm{Sn}\}$

c) A utility/payoff function- set players gains: $\{\mathrm{U} 1, \ldots, \mathrm{Un}\}$

\section{Different Categories of Game}

Games can be distinguished according to various criteria:

a) According to number of players: Usually there should be more than one player. Maximum number of players is finite. A player may be expounded as a nation, or a team comprising many people, companies, associates etc. Game categorized as a one- person, two persons, or n-person ( $\mathrm{n}>2$ ) game.

b) According to rationality of players: A key supposition in many variants of game theory is that the players are rational. A rational player is one who always chooses an action which gives the outcome he most prefers, given what he expects his competitors to do. There can be distinguished two extreme ways. The first one is called 'intelligent' player who is acting rationally. The other extreme is the player who chooses random actions.

c) According to cooperation: Games can be categorized into cooperative and non- cooperative. A game in which players are allowed to cooperate with each other on a joint strategy is called a 'cooperative game'. For example, a cooperative game is a bargaining game between parties in a transaction over the value of a target company. For non- cooperative is basic assumption that individual players can not cooperate. In this game is associated with the analysis of strategic choices. d) Normal and extensive form: The strategic form which is also called normal form is the basic type of game studied in non-cooperative game theory. A game in strategic form lists each player, and the outcomes that result from each possible combination of choices. The extensive form, which is also known as a game tree, is more detailed than the strategic form of a game. It is a complete description of how the game is played over time.

e) Zero-sum and non-zero-sum games: Zero- sum games have the property that the sum of the payoffs to the players equals zero. For example, chess, poker, and most sports game like basketball are zero-sum game. Real- world games are rarely zero-sum game. It is also called constant-sun games. In non-zero-sum games, all players could win or loss together. Most of the games in our real life and the business world are non-zero-sum game. For example, price wars between firms are non-zero-sum games. In non-zero-sum game players have common and conflicting interests (Geckil, 2010).

\section{ii) Game Theory}

Game theory is the logical analysis of situations of conflict and cooperation. Game theory could be formally defined as a theory of rational decision in conflict situations. Model of such situations, as they are conceived in game theory, involve

a) a set of decision makers, called players;

b) a set of strategies available to each player, courses of action which he or she may choose to follow;

c) a set of outcomes, the strategies chosen by each player determine the outcome of the game;

d) a set of payoffs accorded to each player in each of the possible outcomes. (Rapoport, 1974, p.1) 
So, Game theory is the study of how players should rationally play games. Each player would like to the game to end in an outcome which gives him as large a payoff as possible. He has some control over the outcome, since his choice of strategy will influence it.

The field known as 'game theory' was introduced in the last century by mathematicians and economists as a tool to analyze both economic competition and political conflicts. Two distinguished game theorists Robert Aumann and Oliver Hart, explain the attraction in the following way:

Game Theory may be viewed as a sort of umbrella or 'unified field' theory for the rational side of social science, where 'social' is interpreted broadly, to include human as well as non- human players (computers, animals, plants) ... It does not use different, ad hoc constructs ... It develops methodologies that apply in principle to all interactive situations (Aumann and Hart, 1992, P. 3)

The subject of Game theory are situations, where the result for a player does not only depend on his own decisions, but also on the behavior of the other players. Game theory is the theory of independent and interdependent decision making in organizations where the outcome depends on the decisions of two or more autonomous players, one of which may be nature itself, and where no single decision maker has full control over the outcomes (Kelly, 2003).

The concepts of game theory provide a common language to formulate, structure, analyze and eventually understand different strategic scenarios. Game theory is a scientific discipline that investigates conflict situations, the interaction between the agents and their decisions (Hotz, 2006). To perform the analysis of critical situations, Game theory uses not only mathematical apparatus, but also an important tool in economics, political science, law, psychology, philosophy and other disciplines.

\section{iii) Background and impact of Game Theory}

Game theory has been widely recognized as an important tool in different fields. The developments of Game theory is largely broadened. The initial discussion of game theory occurred in a letter written by James Waldegrave in 1713. In this letter, Waldegrave provides a mixed strategy solution to a two-person version of the card game le Her. James Madison made what we now recognize as a game theoretic analysis of the ways states can be expected to behave under different system of taxation. The earliest example of a formal game-theoretic analysis is the study of a dupopoly by Antoine Cournot in 1838. His publication Researches into the Mathematical Principles of the Theory of Wealth presents a solution that is a restricted version of the Nash equilibrium (Crider, 2012, p. 4). A formal theory of games was suggested by the mathematician Emile Borel in 1921, which was furthered by the mathematician John Von Neumann in a "theory of parlor games" in 1928.

John Von Neumann and Oskar Morgenstern published the Theory of Games and Economic Behavior in 1944. It introduced the economic and mathematical basis for the field we now call 'Game theory'. This book contained much of the basic terminology and problem setup that is still in use recent times. Von Neumann and Morgenstern established the field that economic and social questions can often be described as mathematical models of suitable games of strategy. This gigantic work provides the method for finding mutually consistent solutions for two-person zero-sum games (Geckil and Anderson, 2010). 
Game theory became closely associated with the Rand Corporation after the second world war. The Rand standing for $\mathrm{R}$ and $\mathrm{D}$ ) corporation was a private company spun off from the US Air Force at the end of the war and it was specially concerned with the prospects of inter-continental nuclear warfare. Game theory was obviously relevant to this task and as a result the organization championed its development by hiring as consultants Von Neumann and other central figures in the development of Game theory, like John Nash, Duncan Luce and Howard Raiffa (Heap and Varoufakies, 1995).

In 1950, game theory developed dramatically, when John Nash developed game theory tools and concepts for general noncooperative theory and cooperative bargaining theory. He introduced what is now called the "Nash equilibrium" of a strategic game in 1951. Game theory was broadened theoretically and applied to problems of war' political science and philosophy in the 1950's and 1960's. British philosopher R.B. Braithwaite in his book Theory of Games as a Tool for the Moral Philosopher was applied to philosophy in 1955. In this book, Braithwaite provides how games can be used to arrive at moral and ethical decisions (Geckil and Anderson, 2010).

As a specialized field game theory was established by great mathematicians and economists, the last quarter of the twentieth century and early 2000s. Game theory acknowledged special attention in 1994 with the awarding of the Nobel prize in Economic science to: John Harsanyi, John Nash and Reinhard Selten. Game theorists Thomas Schelling and Robert Aumann was awarded Nobel prize in 2005. Schelling worked on dynamic models, early examples of evolutionary game theory. Aumann for having enhanced our understanding of conflict and cooperation through game-theory analysis. In 2007, Roger Myerson, together with Leonid Hurwicz and Eric Maskin, was awarded the Nobel prize in Economics "for having laid the foundations of mechanism design theory" with game theory structure and its design. Alvin E. Roth and Lloyd S. Shapley were awarded the Nobel Prize in Economics "for the theory of stable allocations and the practice of market design” in 2012. And, in 2014 the Nobel Prize went to game theorist Jean Triole. Eleven game theorists have got the Nobel Prize in Economics and John Maynard Smith was awarded the Crafoord Prize for his application of game theory (Aumann, 1991).

\section{iv) Game Example - Analysis of "The Prisoner's Dilemma”}

Classic and probably the most discussed example of the use of Game Theory is the Prisoner's Dilemma. The 'Prisoner's Dilemma' is an example of a two-person non-zero-sum game, in which some outcomes are preferred by both players to other outcomes. It is a subset of game theory and is simplified to give each of two parties two decisions- resulting in $2 * 2=4$ possible outcomes.

In 1950 Melvin Dresher and Merril Flood at the RAND Corporation considered Game 1.1 to illustrate that a non-zerosum game could have an equilibrium outcome which is unique, but fails to be Pareto optimal.

Rose

\begin{tabular}{|l|l|l|}
\hline & A & B \\
\hline A & $(0,0)$ & $(-2,1)$ \\
\hline B & $(1,-2)$ & $(-1,-1)$ \\
\hline
\end{tabular}

Game 1.1: The original Prisoner’s Dilemma. A is “ don’t confess”; B is "Confess”. 
Later, when presenting this example at a seminar at Stanford University, Albert W. Tucker told a story to go with the game and formalized (Straffin, 1993, 73). The story of Prisoner's Dilemma is as follows:

Two prisoners accused of the same crime are kept in separate cells. Only a confession by one or both can lead to conviction. If neither confesses, they can be convicted of a lesser offense, incurring a penalty of one month in prison. If both plead guilty of the major crime, both receive a reduced sentence, five years. If one confesses and the other does not, the first goes free (for having turned State's evidence), while the other receives the full sentence, ten years in prison. Under the circumstances is it rational to admit guilt or to deny it?" (Rapoport, 1974, P. 17).

In this situation both suspects offered these options:

a) If both suspects not confess, they will be arrested for 1 month.

b) If both suspects confess, they will be arrested for 5 years.

c) If one suspect confesses and the other did not, then one who confessed will get free (0). The other one who did not confess will be arrested for 10 years.

The constants involved in this situation, analysis need to be introduced here: Therefore, let

$\mathbf{R}=$ Reward for mutual cooperation= Payoff for Cooperation against cooperation (Payoff for $\mathrm{C} / \mathrm{C}$ ).

$\mathbf{S}=$ Sucker's payoff $=$ Payoff for Cooperation against Defection (C/D)

$\mathbf{T}=$ Temptation to Defect $=$ Payoff for Defection against Cooperation (D/C)
$\mathbf{P}=$ Punishment for Mutual Defection = Payoff for Defection against Defection (D/D).

The general form of Prisoner's Dilemma conditions: $T>R>U>S$ and $\mathrm{R}>(\mathrm{S}+\mathrm{T}) / 2$

The situation can be described by a payoff matrix:

\begin{tabular}{|l|l|l|}
\hline & C & D \\
\hline C & $(\mathbf{R}, \mathbf{R})$ & $(\mathrm{S}, \mathbf{T})$ \\
& $(\mathbf{0 , 0 )}$ & $(-2,1)$ \\
\hline D & $(\mathbf{T}, \mathbf{S})$ & $(\mathbf{P}, \mathbf{P})$ \\
& $(\mathbf{1 , - 2 )}$ & $(-1,-1)$ \\
\hline
\end{tabular}

Figure1.2: Prisoner's Dilemma. Here, C: Cooperative \& D: Defect

\section{V) Some Applications of Game Theory}

Game theory is not just theory, it's also applied in many areas. The use of game theory has expanded and applied to economics, business, biology, computer science, political science, psychology and philosophy. Game theory can describe a number of specific phenomena: interpersonal relations, competition, war and political affairs. From a historical aspects game theory can be identified in the works of ancient philosophers. It is applied to develop theories of ethical or normative behavior. Economists and philosophers have applied game theory to understand rational behavior. There are some applications of game theory in the below: 


\section{Economics and Business}

Game theory is an important tactics applied in mathematical economics and business for modeling the patterns of behavior of interacting agents. According to P.A. Samuelson and W. D. Nordhaus:

Economic life contains many situations with strategic interaction among firms, households, governments or others. Game theory analyzes the way that two or more parties, who interact in an arena such as a market, choose actions or strategies that jointly affect all participants (Samuelson, 2010, P. 207).

Economists use 'Game Theory' as a tool to analyze economic competition, economic phenomena such as bargaining, mechanism design, auctions, voting theory; experimental economics, political economy, behavioral economics etc.

Game theory is applied for determining different strategies in the business world. It offers valuable tools for solving strategy problems. Many business strategies are short or long-term plans to achieve sustainable profitability. A business can often successfully position in the market with right strategy and a business will suffer in the long run with wrong strategy.

Strategic behavior occurs regularly among executives, manager and investors in business world. They must decide to enter into new markets, launch new products, invest now or lose the opportunity to invest and make pricing and purchasing decisions. Game-theoretic models are very potential tools for analyzing firm decisions. Game theory models forces each player to consider the actions of others when picking their strategy, in which one player may respond to the moves of his competitor. It provides significant benefit to a decision maker (Geckil and Anderson, 2010).

\section{Game Theory in Politics:}

Game theory is widely used in political affairs, which is focused on the areas of international politics, war strategy, war bargaining, social choice theory, Strategic voting, political economy etc. Game theory is an effective tool in the hands of diplomats and politicians to analysis any situation of conflict between individuals, companies, states, political parties. Rationality of actors and the choice of strategies are one of the basic assumptions of game theory. Game theory seems to be useful tool for research on terrorism because it captures the interaction between attacked subject and terrorist organization, when the steps are interdependent and therefore cannot be analyzed separately (Sandler and Arce M, 2003).

By using Prisoner's dilemma, we will focus situation where governments choose between active and reactive counter terrorism policies.

Let,

There are two countries- Bangladesh and India. Both countries face common threat of terrorist attacks, and both must agree on whether or not to jointly apply active counter- terrorism policy.

\begin{tabular}{|l|l|l|l|}
\multicolumn{1}{c}{} & \multicolumn{2}{c|}{ Bangladesh } \\
\cline { 2 - 4 } & & active & reactive \\
\cline { 2 - 4 } India & active & $(4,4)$ & $(-2,6)$ \\
\cline { 2 - 4 } & & & \\
\cline { 2 - 4 } & reactive & $(6,-2)$ & $(0,0)$ \\
\hline
\end{tabular}


We assumed that active policy for individual countries gains benefits of 6 and costs of 8 for country that applied active policy. If the India is applying active policy and the Bangladesh will be the state that will only get benefits associated with it, then Bangladesh will have the advantages of the 6 . India gets $-2(6-8)$. Cost of 8 shall be deducted from the benefits of 6 . Otherwise, if the India is a free-rider, the benefits are reversed.

If both countries are active policy, then everyone gets the benefit of $-4(8-2 \times 6)$.

The result is prisoner's dilemma game, in which no country wants to apply active counter-terrorism policy.

\section{Evolution of cooperation}

Game theory is applied to analyze many seemingly anomalous natural phenomena in biology. The evolution of cooperation is a fundamental problem in biology because unselfish, altruistic actions apparently contradict Darwinian selection. Game theory offers to an evolutionary context, has become an invaluable tool to address the evolution of cooperation. The most noted mechanisms of cooperation are direct and indirect reciprocity and spatial structure (Heiko Hotz, 2006).

The concept of cooperation and altruism- as it is analyzed by evolutionary biology- is close to the notion of 'Tit for Tat' which is an effective strategy first introduced by Anatol Paport. He tries to show that self- interested persons will cooperate to promote their general interest. Robert Axelrod (1984) tries to demonstrate the evolutionary feasibility of reciprocal altruism and cooperation with each other in a Tit for Tat' prisoner's dilemma game.

\section{Game Theory and Philosophy}

Game theory and Philosophy are connected in many ways. Game theory has been used as a tool in philosophical discussions. Philosophers have promisingly attracted in game theory as it offers a way of interpreting the conception of Philosophers. There are different areas of Philosophy that interact in a fruitful way with game theory.

\section{Kant's Categorical Imperative}

German Philosopher Immanuel Kant's moral philosophy is rooted in his formulation of the categorical imperative. It refers to the 'supreme principle of morality' from which all our moral duties are derived. Kant's first formulation of the categorical Imperative, the Formula of Universal Law: "Act only according to that maxim whereby you can at the same time will that it should become a universal law" (Kant, 1785, p. 46).

The categorical imperative can apply in game theory. In terms of game theory, this statement can be restated as follows: "Choose only a strategy which, if you could will it to be chosen by all the players, would yield a better outcome from your point of view than any other" (Nitti, 2014, p. 36). This statement, then becomes a solution to the Prisoner's Dilemma. That is, according to Kant's categorical imperative, only a cooperative choice can result. This is because the personal choice of defecting, if 'made universal', is in contradiction to one's personal interest.

\section{Epistemology}

Epistemology, the study of knowledge, which inquires about the nature, source, status and extent of knowledge. Game theory challenged philosophers to think in terms of interactive epistemology. It covers players have common knowledge of the structure of the game and their mutual rationality. 
According to Cristina Bicchieri: "The epistemic approach to game theory provides a formal analysis of strategic reasoning, making explicit player's knowledge or beliefs about the structure of the game and the strategies, knowledge and beliefs of other players” (2007, p. 22).

\section{Rational Behavior and Decision Theory}

Game theory is a useful and potential tool for the understanding of human affairs. Game theory has been expounded as a part of a general theory of Rational Behavior. Rationality is a normative concept, which indicates to what we should do in order to attain a given end or objective. When we are thinking of behavior involving a choice of the best means available for achieving a given end that is 'rational behavior' (Harsanyi, 1980). Rational behavior models are widely used in game theory. According to Von Neumann and Morgenstern: 'We wish to find the mathematically complete principles which define 'rational behavior' for the participants in a social economy, and to derive from them the general characteristics of that behavior' $(1944$, p. 31). Game theory as a theory of rationality advices what agents (players) should do in specific interactive situations, given their preferences.

Decision theory is the analysis of the human behavior, which concentrates on identifying the 'best' decision option to decision maker. Decision theory provides the rationality of decisions in the light of preferences over outcomes and beliefs about the likelihood of outcomes. Game theory is closely related to decision theory, which studies inter-actions between self-interested players. Game theory along with decision theory analyzes interdependent decision problems between rational, strategic agents. The basic difference between the two that: Decision theory treats all outcomes as exogenous events, 'moves of nature'; whereas in Game theory the prime source of uncertainty for an agent is the way other agents will behave (Cristina, 2007). After analyzing some of the application of the game theory in philosophy we assumed that, game theory has been the object of philosophical inquiry.

\section{Concluding Remarks:}

Game theory is the formal study of conflict and cooperation between intelligent rational decision-makers. It has been a powerful analytical tool to help us understand the phenomena that can be observed when decision makers interact. Game theoretic models have become increasingly sophisticated and in consequence, much more powerful and useful. It has been successfully applied to a wide variety of disciplines including economics, sociology, psychology, philosophy. Game theory has helped sharpen our intuitions, allowing a 'rational reconstructions' of different ideas, norms, values among agents (players) for significant philosophical expositions. At the end of discussion, we would like to quote from British prominent writer Charles Lamb's (1775-1834) famous work Essays of Elia: 'Man is a gaming animal. He must always be trying to get the better in something or other'.

\section{References}

1. Aumann, R, and S. Hart (eds.). (1992). Handbook of Game Theory. Amsterdam: North- Holland.

2. Aumann, R. (1991). Game Theory. In Eatwell John, Milgate Murray, and Newman Peter (eds.). The New Palgrave: A Dictionary of Economics, London: Palgrave Macmillan.

3. Bicchieri, Cristina. (2007). Game Theory: Some Personal Reflections. In V.F. Hendricks and P.G. Hansen (eds.), Game Theory: 5 Questions, Copenhagen: Automatic Press. 
4. Bicchieri, Cristina, and Sillari, Giacomo. (2005). Game Theory and Decision Theory. In Borchert, Donald (ed.). The Encyclopedia of Philosophy, $2^{\text {nd }}$ ed., Detroit: Macmillan.

5. Crider, Lucrecia. (2012). Introducing Game Theory and its Applications. Delhi: Orange Apple Publication.

6. Prisner, Erich. (2014). Game Theory Through Examples. Washington, DC: The Mathematical Association of America.

7. Geckil, Ilhan, and Anderson, Patrick. (2010). Applied Game Theory and Strategic Behavior. London: CRC Press.

8. Harsanyi. (1980). Essays on ethics, social behavior and scientific explanation, Berlin: Springer.

9. Heap, Hargreaves, and Varofakis, Yanis. (1995). Game Theory: A Critical Introduction. London: Routledge.

10. Hotz, Heiko. (2006). A Short Introduction to Game Theory.

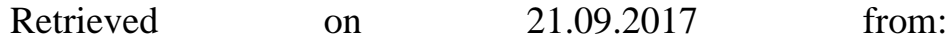
http://www.theorie.physik.lmu.de/

11. Kant, Immanuel. (1785). Fundamental Principles of the Metaphysic of Ethics. Trans. T.K. Abbott. (1962). $10^{\text {th }}$ ed. London: New Impression.

12. Kelly, Anthony. (2003). Decision Making using Game Theory. Cambridge: Cambridge University Press.

13. Neumann, John von and Morgenstern, Oskar. (1944). The Theory of Games and Economic Behavior. Princeton: Princeton University Press.

14. Nicola De Nitti (2014). An Introduction to Game Theory and Its Applications. Retrieved on 17.08.2017 from: http://www.matematicamente.it/21 gennaio/

15. Rapoport, Anatol (ed.). (1974). Game Theory as a Theory of Conflict Resolution. USA: D. Reidel Publishing Company.
16. Samuelson, P A. and Nordhaus, W.D. (2010). Economics. New York: McGraw Hill.

17. Sandler, T, and Arce M, Daniel. (2003). Terrorism and Game Theory. vol. 34, issue 3, International Simulation and Gaming Association (ISAGA).

18. Straffin, Philip. (1993). Game Theory and Strategy. Washington, DC: The Mathematical Association of America. 